\title{
0 [fazer do] Cururu sul-mato- grossense: um recorte sob a perspectiva dos conceitos de tempo e resistência
}

\author{
The doing and being of the state of Mato-Grosso-do-Sul estate: a cutout under \\ the perspectives of time and resistance
}

José Gilberto Garcia ROZISCA ${ }^{44}$

\begin{abstract}
RESUMO: Nosso estudo versa sobre a narrativa do cururueiro e a poética do Cururu, que é, por sua origem, uma prática relacionada a valores religiosos, éticos e de companheirismo, ao mesmo tempo em que é vivenciada como uma brincadeira entre seus praticantes. O objetivo é tratar do Cururu discutindo os conceitos de tempo e de resistência na narrativa, reconhecendo que resistir tem a ver com a capacidade de opor-se a um sistema de força contrária, além de ser a capacidade de lutar em defesa de algo, em face do peso dos princípios e dos valores de dada cultura. Utilizamos o método de pesquisa bibliográfica, tomando por base as cantigas de Cururu executadas em Mato Grosso do Sul dispostas em obras como o Dossiê de Registro do Modo de Fazer Viola-de-Cocho, do IPHAN; a dissertação de mestrado de Eunice Ajala Rocha; e a entrevista do mestre cururueiro Agripino Soares Magalhães, para a série audiovisual A História da Nossa Gente do site Diário Corumbaense. O diálogo com referenciais teóricos passou por estudiosos como Alfredo Bosi, Benedito Nunes e Ecléa Bosi. A pesquisa mostrou a pertinência de tratar tanto a narrativa do cururueiro quanto da poética das cantigas sob a perspectiva dos conceitos propostos.
\end{abstract}

PALAVRAS-CHAVE: Cururu; Tempo; Resistência

\begin{abstract}
Our study focus on the narrative of 'cururueiro' and the poetic that sorrounds 'Cururu', which is, by its origns, a practice related to religious, etic and friendship values, at the same time as it is faced as a playful time by its players. The objective is to register Cururu toward the concept of time and resistance into the narrative, recognizing that resisting is related to the capability of being on the contrary forces of a system, as well as the capacity to fight in defense of something, due to the principles and strengh values from a particular culture. The bibliographic method has been used, taking some Cururu popular songs played in the state of Mato Grosso do Sul as popular artwork pieces registered in specific books like the way to produce viola-de-cocho, the IPHAN register book file, Eunice Ajala Rocha master registration and the given interview of head master cururueiro Agripino Soares Magalhães to the audiovisual The History of our People series to Diario Corumbaense site. The theoretical discussion goes through Alfredo Bosi, Benedito Nunes e Ecléa Bosi. This research
\end{abstract}

\footnotetext{
${ }^{44}$ Mestrando em Estudos de Linguagens na Universidade Federal de Mato Grosso do Sul; E-mail: jgrozisca@yahoo.com.br.
} 
shows the relevance not just treating the cururueiro narrative, but also facing the poetic popular songs beneath the perspective of these proposal concepts.

KEY WORDS: Cururu; Time; Resistance.

\section{INTRODUÇÃO}

Reconhecer que o tempo muda o modo como se enxerga certo lugar, certa ação, certos acontecimentos que ficam registrados na memória de um passado, a forma como encaramos o presente e a expectativa que temos para o futuro, isso pode importar para o nosso estudo.

Benedito Nunes (1995) lembra que filósofos como Santo Agostinho voltaram suas reflexões, em algum momento, para tratar do tempo, mas ainda assim a imprecisão de um conceito exato sobre ele emerge e paira nas mentes de quem se propõe a pensar, nas palavras do Santo, carregadas pelo tom da decepção, "o que é, por conseguinte, o tempo?" (Apud NUNES, 1995, p.16). Talvez tal pergunta permaneça sem uma resposta, mas, adiante, trataremos um pouco sobre o que nos importa acerca do tempo.

Outra palavra que ganha peso no desenrolar deste estudo é resistência. Alfredo Bosi nos ensina o que parece ser óbvio, que resistir tem a ver com oposição, sendo a capacidade de opor-se a um sistema de força contrária, além da leitura de resistência como a capacidade de lutar em defesa de algo, pelo peso dos princípios e valores de cada um. O Cururu sul-mato-grossense é uma manifestação que podemos julgar resistente ao próprio tempo, insistente no tempo.

Lembrar também é uma forma de resistir, mas o que foi atitude de resistência pode passar a ser somente uma lembrança, a ser esquecida no tempo. E o tempo é irrecuperável, e as situações que ficam perdidas nele também restam perdidas, tanto para as gerações atuais quanto para as que virão.

Procuramos, então, falar de tempo e de resistência no Cururu como manifestação cultural, nas cantigas e na fala dos cururueiros, procurando, também, tratar e entender como resistente [pela luta ideológica em defesa da manifestação] 
até mesmo a existência e o que se fala, de/em outros textos, sobre o Cururu e seus fazedores.

\section{O CURURU EM TELA}

Consideramos o ensinamento de Benedito Nunes (1995, p. 06) de que pelo entendimento que se tem hoje, "[...] cabe chamar de narrativa a títulos diferentes, ao mito, à lenda e ao caso, formas simples, literariamente fecundas, mas que não são propriamente literárias como o conto, a novela e o romance; às várias espécies de relatos orais e a modalidade de escrita [...]". Assim, justificamos nosso interesse em por em tela tão peculiar objeto textual, mesmo compreendendo que o elemento tempo geralmente aparece de modo implícito em formas narrativas como as que apresentaremos.

Para sermos melhor entendidos, cumpre-nos explanar o que vem a ser o Cururu. Os mais atentos às expressões culturais do Brasil, mais notadamente das práticas realizadas nos estados de Mato Grosso e Mato Grosso do Sul, ou pelo menos os conhecedores de manifestações do interior paulista [região do Médio Tietê], talvez já tenham ouvido o termo Cururu ser pronunciado. Quem sabe até já puderam presenciar tal manifestação folclórica sendo realizada, o que é bastante difícil nos dias atuais, ao menos em Mato Grosso do Sul.

Vale destacar que, mesmo ciente da existência de um Cururu paulista, esse não é objeto do nosso estudo. Nosso empenho põe em tela apenas a manifestação tratada como Cururu mato-grossense, em sentido amplo, pois o termo foi forjado antes da divisão do estado de Mato Grosso, ocorrida em 1978. Acrescentamos, ainda, um recorte para destacar apenas o que foi praticado [e ainda o é] na região de Corumbá-MS, por isso justificamos o título dado a este artigo, tratando a manifestação como Cururu sul-mato-grossense.

Para poder tratar sobre o assunto, tomamos por base a pesquisa realizada pela historiadora-folclorista Eunice Ajala Rocha (1928-2013), relatada em sua 
Dissertação de Mestrado, defendida no ano de 1981, Uma expressão do folclore mato-grossense: cururu em Corumbá, que tratou essencialmente sobre o fato folclórico que é objeto do nosso estudo - o Cururu.

Segundo a pesquisadora, o Cururu vem a ser "[...] uma 'brincadeira' que envolve movimento, música, cantoria e sapateado, na qual tomam parte somente homens. Encerra duplo sentido, de religiosidade e lazer que se entrelaçam e se unem de acordo com o motivo que leva o grupo a se reunir (...)" (ROCHA, 1981, p. 33).

Em Corumbá o termo Cururu encerra dois sentidos: no mais restrito deles, a palavra aparece como sinônimo de "brincadeira", na qual as duplas se encontram para tocar e cantar seus versos, seja em ensaios, seja em celebrações. Em sentido mais amplo, Cururu designa a "festa" como um todo: pode ser um festejo em homenagem a um santo ou mesmo uma celebração das bodas de um casal, quando, após a cerimônia religiosa, a brincadeira será realizada.

Manifestação folclórica complexa, o Cururu é permeado de simbolismo, seja na sua própria execução, seja no aspecto material, com o feitio dos instrumentos musicais que serão utilizados, principalmente a viola-de-cocho, que é fabricada pelos próprios mestres cururueiros a partir de uma peça de madeira única.

Eunice Rocha (1981, p. 36) destaca o caráter de "[...] elemento ordenador das cerimônias religioso-folclóricas" do Cururu, pois suas toadas, assim chamadas as músicas ou cantigas produzidas, além de estimular os fiéis a participarem da cerimônia, serviam de orientação e direção das cerimônias, marcando os momentos de início da reza e da procissão, além de outras etapas, como a colocação da bandeira do santo e da coroa no mastro, e o içamento do mesmo. A folclorista descreve a realização do Cururu em uma cerimônia da seguinte forma:

Os cururueiros em frente ao altar, em fila dupla, cantam parados, e quando precisam se comunicar, falam baixinho, quase num sussurro em sinal de respeito e devoção. Começam pela "louvação" [...] Nela, pedem licença para cantar, homenageiam os santos e as pessoas que consideram importantes. Os nomes dos donos da casa, dos santos, e das pessoas que 
estão prestigiando a festa com a sua presença são citados por várias vezes, de permeio às letras dos versos. Após cumprirem a "obrigação" com o/a santo/a a cantoria de CURURU prossegue durante o ciclo da festa numa demonstração inconteste de resistência física que os caracteriza, além da motivação proporcionada pela oportunidade de homenagear o/a santo/a e pela satisfação do encontro com os amigos. (ROCHA, 1981, p. 34)

Com a ideia de trazer uma referência histórica sobre o Cururu, destacamos aquilo que é apresentado no livro Modo de Fazer Viola-de-Cocho, publicado pelo Instituto do Patrimônio Histórico e Artístico Nacional - IPHAN, em 2009. A obra é resultado do dossiê elaborado para o processo de Registro, no Livro dos Saberes, da técnica de fabricação da viola-de-cocho como Patrimônio Cultural brasileiro.

No título de Registro protetivo, constante no próprio Dossiê, notamos menção ao "[...] complexo musical, coreográfico e poético associado do cururu e do siriri" (IPHAN, 2009, p. 82). Consta no Dossiê a seguinte informação:

\footnotetext{
A referência bibliográfica mais antiga ao cururu na região foi identificada no livro Entre os Aborígenes do Brasil Central, onde o etnólogo alemão Karl von den Steinen descreve as etapas de uma apresentação de cururu conforme ocorrências nas festas de santo em Cuiabá no final do século 19. $[\ldots]$

Posteriormente, no início do século 20, Max Schmidt identifica e descreve a prática da dança do cururu entre os índios guatós em pesquisa na região pantaneira, atual Mato Grosso do Sul. (IPHAN, 2009, p. 49)
}

Encontramos nas referências bibliográficas do Dossiê que o livro Entre os Aborígenes do Brasil Central foi publicado em 1940. Na dissertação de Eunice Rocha (1981) vimos que o etnólogo alemão Karl von den Steinen fez sua pesquisa na região cuiabana entre os anos de 1887-1888, o que demonstra como é antiga a presença do Cururu no oeste do Brasil.

O pesquisador João Carlos de Souza publicou, em 2004, o artigo O caráter religioso e profano das festas populares: Corumbá, passagem do século XIX para o 
$X X$, no qual aponta uma interessante referência ao cururu, veiculada em um periódico de 1880 na cidade de Corumbá:

\begin{abstract}
$\mathrm{Na}$ imprensa, encontramos uma das primeiras referências sobre essa dança no periódico $O$ Iniciador, de outubro de 1880. Tratava-se de uma reclamação de alguns moradores do acampamento de São Francisco Xavier, pedindo providências às autoridades competentes "afim de q'os amantes de tal divertimento Cururú deixe descançar a humanidade altas horas da noite, pois que quem trabalha de dia quer descançar aquellas horas ... Assinado: um que não é vadio". (SOUZA, 2004, p. 339)
\end{abstract}

Mais do que uma referência histórica, resta nessa passagem uma inferência sobre o sujeito praticante do Cururu, que fora chamado, mesmo que indiretamente, de "vadio". Sobre essa característica de brincar, atribuída ao Cururu, é porque a prática da manifestação durava muitas horas, chegando a varar as noites. Eunice Rocha (1981) menciona que era comum que as festas seguissem pela noite toda, pelo dia, e até por vários dias, dependendo da disponibilidade dos cururueiros. Porém, entendemos que os cururueiros daquela época, assim como os de hoje, nada tinham de desocupados, eram sim trabalhadores ou já aposentados, de classe popular.

Mencionada a referência histórica sobre a presença do Cururu na região pantaneira, destacamos um outro ponto importante para este estudo e que remete às origens da manifestação. Câmara Cascudo (1972), no Dicionário do Folclore Brasileiro, faz referência à opinião de Mário de Andrade, que citamos abaixo. E, corroborando com o pensamento de Mário de Andrade, encontramos a citação de Maria Amália Giffoni, constante na pesquisa de Eunice Rocha (1981, p. 86). Ambos discutem a provável origem do Cururu como sendo um instrumento catequético jesuítico.

Mário de Andrade escreve: “... os primórdios coreográficos desta dança têm tal e tão forte sabor ameríndio, pelo que sabemos das danças brasílicas com a cinematografia atual, que não hesito em afirmar ser o cururu uma primitiva dança ameríndia, introduzida pelos jesuítas nas 
suas festas religiosas, fora (e talvez dentro) do templo. E esse costume e dança permaneceram vivos até agora" (...). (CASCUDO, 1972, p. 335)

\begin{abstract}
Segundo Maria Amália Giffoni, o Cururu "Como dança parece ser de origem ameríndia, introduzida pelos jesuítas na catequese, que lhe anexaram louvação e cantos portugueses, com temas religiosos. Os missionários inseriram o Cururu em festas cristãs e delas se valeram para transmitir conhecimentos aos doutrinandos. Lançaram mão, já no primeiro século do descobrimento, de uma manifestação coreográfica como veículo educativo". A autora situa com clareza a dança indígena como elemento natural, a matéria prima de que se valeram os jesuítas para utilizá-la como veículo empregado na introdução dos conceitos cristãos. (ROCHA, 1981, p. 86)
\end{abstract}

Marlei Sigrist, pesquisadora da cultura popular sul-mato-grossense, corrobora com as opiniões expostas acima. Para ela, a cruz e a espada foram as armas que os conquistadores portugueses e espanhóis mais utilizaram para garantir o domínio das terras brasileiras e da América Espanhola. Usaram instrumentos que mantivessem a ordem social durante a colonização e para a manutenção das terras, um dos quais foi o uso das artes - música, teatro, pintura - que "[...] por meio de temas religiosos, incutiam sentimentos de obediência, submissão e acriticidade" (SIGRIST, 2008, p. 52).

Sigrist complementa seu raciocínio ao lembrar que as missões jesuíticas acabaram influenciando as manifestações culturais e a educação religiosa das terras conquistadas por Portugal e Espanha. Afirma também que aquilo que hoje conhecemos como religiosidade popular é resultado da lacuna que os jesuítas deixaram após serem expulsos do Brasil. Vejamos:

Quando os jesuítas foram expulsos do país, deixaram um vazio na disseminação da doutrina cristã, o que levou muitas pessoas a assumirem a função de pregadores, interpretando as palavras sagradas de acordo com seus parcos conhecimentos. As interpretações que deram às passagens bíblicas foram as mais diversas, resultando no que hoje se denomina religiosidade popular. Isso se repetiu em todo o interior brasileiro, inclusive nos sertões de Mato Grosso. (SIGRIST, 2008, p. 53) 
Cumprida a explanação sobre o que é o Cururu, cabe-nos a tarefa de direcionar o estudo. De tudo o que foi exposto até agora trataremos as informações procurando alinhá-las com dois elementos: o tempo e a resistência que permeiam a narrativa do mestre cururueiro e/ou o que se documenta sobre o Cururu.

Continuaremos a nos pautar na obra da historiadora-folclorista Eunice Ajala Rocha, cuja pesquisa data do final da década de 1970 e início dos anos de 1980; nas citações dos relatos dos próprios cururueiros que constam no Dossiê do IPHAN; e ainda, no episódio da série A História da Nossa Gente, do site de notícias Diário Corumbaense, cuja entrevista foi feita com o mestre cururueiro Agripino Soares Magalhães.

E por que falar sobre tempo e resistência? O que, afinal, teríamos a dizer sobre tais assuntos, relacionando-os com uma manifestação cultural como o cururu?

Para lidar com a provocação do tema, apegamo-nos aos ensinamentos de alguns estudiosos, dentre eles, Alfredo Bosi, que tratou sobre a temática da resistência na poesia e na narrativa. Segundo ele, o conceito de resistência não é estético, mas originalmente ético. Entendemos, com isso, que a resistência figura na orientação do comportamento, na vontade; ela, por si, faz parte de um conjunto de preceitos e valores de um indivíduo, de um grupo social ou de uma sociedade como um todo.

Alfredo Bosi diz que "[...] resistir é opor a força própria à força alheia [...] o cognato próximo é in/sistir; o antônimo familiar é de/sistir" (BOSI, 1996, p. 11). Valendo-se da relação com sua vontade íntima, com raízes fincadas nos seus valores, o sujeito impõe resistência à outra força, exterior a ele próprio.

A continuidade da prática do Cururu seria, pois, uma atitude de resistência perante o universo que rodeia os cururueiros. Se para eles perduram os valores dos ensinamentos bíblicos e da religiosidade, do respeito aos ensinamentos antigos, da amizade, para o restante do mundo resta a desconformidade. 
Resistir, então, vem a ser uma ação diante do próprio tempo, intrincada na vida e nas palavras de cada um dos narradores que ousamos tratar. Os valores do Cururu perduram nas narrativas orais; a manifestação, por si, existe apenas na memória de quem a pratica, sem registro, sem perspectiva de continuidade. Da mesma forma, as falas desses sujeitos são marcadas pelo peso de suas memórias, e para Ecléa Bosi “[...] a memória é um cabedal infinito do qual só registramos um fragmento" (BOSI, 1994, p. 39), um fragmento que nada mais é do que uma parcela do tempo.

Para melhor elucidar o que nos propusemos a expor, apresentaremos abaixo alguns excertos que julgamos interessantes para compor nosso estudo. A primeira delas consta na dissertação de Eunice Rocha, na parte em que ela trata do significado do Cururu e, valendo-se primeiramente da visão dos próprios cururueiros, inicia o texto com uma citação do que podemos tratar como sendo uma construção coletiva, pois dá crédito a três informantes sobre a mesma fala - "dona" Maria Divina de Souza, "seo" Agripino Soares Magalhães e "seo" João Teodoro da Silva. Vejamos:

\footnotetext{
Quando se indaga de um Cururueiro a respeito da origem do Cururu em Corumbá a resposta que se recebe identifica-se com todas as outras. "Cururu é tão antigo quanto o mundo, porque foi nosso Senhor Jesus Cristo que deixou p'ra nós. Quando ele andou pelo mundo visitou muitos lugares. Um dia encontrou um baile, observou e não gostou. Virou as costas e foi embora. Depois, em suas andanças encontrou a 'brincadeira' de Cururu aprovou e ficou". (ROCHA, 1981, p. 50, grifos nossos)
}

Na época, a pesquisadora destacou o fato de essa explicação parecer simplista e mesmo assim lembrou que, implicitamente, tal fala revela "um mundo de valores contido num espaço ilimitado" (ROCHA, 1981, p. 50), se for levada em conta a concepção religiosa dos falantes. Dá-nos a impressão de que a função original do Cururu acabou perdurando no tempo se considerarmos válida a ideia de que a prática foi introduzida pelas razões catequéticas dos Jesuítas, acabou resistindo na ética das 
famílias e passou de geração a geração, agregando inclusive novos adeptos catequizando-os.

Voltando aos ensinamentos de Alfredo Bosi, "[...] a ideia de resistência, quando conjugada à de narrativa" pode ser tida por duas maneiras, sem que uma exclua a outra; na primeira delas "a resistência se dá como tema" da narrativa, já na segunda "a resistência se dá como processo inerente à escrita" (BOSI, 1996, p. 13). Por analogia, tomamos a liberdade de pensar que o processo não se refere somente à escrita, mas também às formas orais. Assim, podemos perceber que existe, na fala que expusemos acima e comum aos três cururueiros, uma resistência, no sentido de negação, quanto a uma possível explicação mais racional para a origem do Cururu.

Aproveitamos também o relato colhido pelos elaboradores do Dossiê do Modo de Fazer Viola-de-Cocho, do IPHAN, logo no início da parte na qual são tratadas as referências históricas da manifestação, em que um dos mestres cururueiros tenta responder a uma pergunta que inferimos ter sido algo do tipo: quem te ensinou o Cururu? ou de onde ele veio?, ao que vem a seguinte afirmação,

\footnotetext{
"É porque foi meu avô que ensinou pro meu pai. Você sabe que, quando eu cheguei, nessa época já vinha daquele tempo todo. Agora, vamos lá saber de que geração veio isso, quem fez isso... Eu mesmo não sei, foi meu pai que me ensinou e o avô dele já brincava, então é muito bom isso aí. Só sei que é muito bom." [Severino de Moura, 80 anos, Corumbá, 2002]. (IPHAN, 2009, p. 38)
}

Para evitar repetições, basta dizer que entendemos a fala desse cururueiro carregada pela mesma intenção da anterior: a busca por fugir do plano de realidade, e mais, o sentimento de transmissão de valores entre as gerações comprovado.

Ecléa Bosi ensina que "[...] há episódios antigos que todos gostam de repetir, pois a atuação de um parente parece definir a natureza íntima da família, fica sendo uma atitude-símbolo. Reconstruir o episódio é transmitir a moral do grupo e inspirar os menores" (BOSI, 1994, p. 424). Isso nos parece mais uma comprovação a respeito 
da resistência, ou melhor dizendo, da insistência em nutrir-se dos ensinamentos e dos "velhos" e levá-los adiante, para além do seu tempo.

A fala do cururueiro é tão permeada com a expressão de valores e ensinamentos que quando se pergunta para ele o que é ou como se faz o cururu, é possível perceber o quão rígida, e de certa forma decorada, é a sua resposta. Podemos perceber isso nas palavras do mestre cururueiro Agripino S. Magalhães, um senhor que completou 98 anos em 2016 e é considerado um ícone da cultura corumbaense, ele que já era líder de um dos grupos de Cururu na época em que a historiadora Eunice Rocha fez sua pesquisa. Abaixo, transcrevemos um trecho da entrevista que ele concedeu ao Diário Corumbaense para a série que mencionamos anteriormente:

\begin{abstract}
O cururu é aquele que é cantado com a viola... somos seis, sete, oito, nove, dez, doze cantadô de cururu. Quatro, seis... toca a viola e o resto toca o ganzá. Canta do mesmo jeito, tocâno viola, tocâno ganzá, cumo que ele quisé. Esses são us cumpanhêro que canta $u$ cururu. Esses são o cururu... o cururu é feito assim (desenhando um círculo no ar)... em roda, e em pé, sapateia, canta. Lóva u santu, lóva as pessoa, lóva o dono da casa, lóva o santo do artá... o cururu é assim, eu canto e o companhêro ajuda, lovano o dono da casa, o juiz o juíza, rei, rainha, alferes de bandêra, capitão de mastro... quarqué uma desse/toca pela viola e canta. Dá um viva ao dono da casa, e os senhor e senhora quiestão... aí viva e torná revivá, aí eu canto uma moda de viola pra eles assim... aqui na, ná/como que é o toque da viola assim ó... (MAGALHÃES, 2013)
\end{abstract}

Essa fala é seguida por uma toada de Cururu, mas quem assiste ao episódio tem a nítida impressão de que o trecho que grifamos é pronunciado ao modo de uma oração, de forma sincopada, ritmada, como se não fosse necessário nem pensar para dizer tais palavras na sequência em que surgem. Num segundo trecho da mesma entrevista, ele fala sobre como um cururueiro deve se apresentar, demonstrando a simplicidade e a religiosidade, mais uma vez: 
borso, não precisa tá mostrano pra todo mundo (risos). E é assim que nós apresentamo pra Deus e o povo. Eles quando tão cantano e dançano, pra mim, é um amor que eu tenho, comigo [...]. (MAGALHÃES, 2013)

Em outro trecho, o mestre cururueiro deixa-nos um exemplo sobre aquilo que a pesquisadora Marlei Sigrist dispôs em sua obra acerca da religiosidade popular. Não bastassem os "ensinamentos" bíblicos aos quais o Cururu faz menção, existem também as crendices populares, como o fato de amarrar fitas no cabo das violas-decocho, vejamos:

Esse é simpatia que nós fazemos, pra envitá de várias coisas, que a gente tem um... não é todo mundo, mas a maioria é assim né... tem inveja do que a gente faz, e bota... olho grande, não sei como-que chama o negócio. O sujeito fica roco, num canta, num fala, num aprende nada. E tudu mundo pra ele é inimigo, e vira um demônio. E com esse-as fitinha aí, quebra $t u d u$-os encanto dele... É lembrança que eu tenhu de uma senhora que já morreu também. Eu foi pra Cuiabá... ela que me ensinô a rezá, Pai Nosso, rezá Creio em Deus Padre... eu tenho essa obrigação de rezá todo dia, pra deitá pra durmi, rezá Creio em Deus Padre. (MAGALHÃES, 2013)

Além da religiosidade catequética, consagrada na própria fala do cururueiro, encontramos nos versos outros elementos relacionados ao tempo. Considerada a marcação cronológica, que é o tempo atual, no qual o Cururu vem resistindo, existe também o tempo psicológico, aquele que reside na lembrança, na memória, e as marcas temporais presentes nas próprias cantigas: a mistura de um tempo bem composto - passado/presente/futuro - e o tempo desapegado de razão fixa, um tempo mítico, constante nas narrativas bíblicas. Além desses, há o tempo [muitas vezes impreciso] de composição das próprias cantigas.

Eunice Rocha colheu, em 1977, na festa de Sant'Ana realizada na residência do senhor Armando Pereira de Oliveira (de alcunha Barro Preto), um exemplo do que procuramos dizer: 
Primeiro veio Sant'Ana

Depois veio Conceição

Não há ninguém que arresiste

Quando fica com sodade

Eu acordo madrugada

Meus olhos pega a chorá

Eu espero amanhecê

E saio p'ra consolá

Meu coração

Depois veio Jesus Cristo

Para nossa salvação

Não há ninguém que arresiste, etc...

Um viva p'ra seu Armando

E à sua devoção

Não há ninguém que arresiste, etc...

Um viva pra dona "Unice"

E sua incentivação

Não há ninguém que arresiste, etc...

(ROCHA, 1981, p. 94)

Destacamos daí, inicialmente, o aparecimento de personagens [nos versos alinhados mais à esquerda] em uma ordem que manifesta sinal de respeito, envolvendo além disso, uma questão temporal. Surge primeiro o nome de Sant'Ana, que seria a homenageada da festa, mas que também é a mãe de Maria, ou seja, a avó de Jesus. Após Sant'Ana, é invocada a figura de Conceição, um dos muitos nomes dados para Maria no catolicismo.

Em seguida o nome de Jesus Cristo é louvado e, cumprida a parte da louvação [ou da licença] às figuras sagradas, surgem os nomes daqueles que estão presentes e são considerados, também, dignos de serem mencionadas no Cururu, na mesma toada [ou poderiamos dizer, ao mesmo tempo] em que os nomes sagrados. 
Vemos a menção ao dono da casa - "seu" Armando - e depois à "dona Unice”, em referência à pesquisadora Eunice Rocha, que estava incentivando os cururueiros, tanto pelo status da sua pesquisa quanto pelas ações junto à comunidade, dando destaque a essa manifestação cultural.

Para tratar da toada de Cururu que expusemos acima, podemos nos valer dos registros que ecoam no tempo, considerando a percepção da historiadora Eunice Rocha acerca do dado que coletou e documentou. Destacamos a análise que, além de tratar sobre a questão dos valores que perduram na vivência de cada uma das pessoas envolvidas em situações de externalização da religiosidade, fala sobre a relação da saudade mencionada nos versos, pois se há saudade é porque existe uma lembrança, e tal lembrança pode confundir-se com o real e o imaginário poético. Vejamos:

Esta toada cantada após o descenso do mastro encerra um mundo de valores, mesclados à ideia central que é o tema religioso. Essa ideia envolve todo o segmento social que faz parte da cultura folk e que se revela através do comportamento unívoco em relação ao culto. Quando as pessoas em coro invocam ao Senhor, quando proferem as suas orações, quando se ajoelham e se levantam com os olhos voltados para os céus, quando baixam as cabeças em sinal de contrição e chegam até as lágrimas, pode-se perceber os caracteres essenciais da realidade imaterial, do caráter sagrado da cerimônia religiosa que está sendo realizada. [...]

Neste caso o conteúdo está representado pelas orações, [...] Ao lado do tema religioso deixam impresso um sentimento lembrado com bastante constância, a saudade (sodade) [...] A saudade que tanto cantam parece ser algo irreal, não de uma realidade vivida, mas daquela que foi sonhada e que o próprio tempo se encarregou de transformar em motivo de saudade como se realidade fosse. (ROCHA, 1981, p. 95-96)

Para tratarmos sobre o tempo na narrativa, nosso estudo lembra os ensinamentos de Benedito Nunes e, assim sendo, não podemos deixar de mencionar algumas de suas palavras, mais notadamente quando o estudioso trata sobre os tempos físico e psicológico. Na reflexão que destacamos, Benedito Nunes expõe que o tempo psicológico é composto por momentos imprecisos, uma relação entre passado e presente cuja tendência é de aproximação ou até de fusão, abrangendo 
lapsos sem comparação, "ao sabor de sentimentos e lembranças". Em contrapartida, o tempo físico é traduzido por mensurações precisas e acaba se apoiando no princípio da causalidade, ou seja, numa relação entre uma forma sucessiva regular - causaefeito, "dizer que um evento antecede outro é afirmar que, sem o primeiro (causa), o segundo (efeito) não existiria" (NUNES, 1995, p. 19).

Acreditamos que o Cururu seja permeado pelos dois tipos de tempo que elencamos acima, mesmo que conste a presença de outras formas temporais, citadas na obra de Benedito Nunes, mas que não colocaremos neste estudo. De qualquer forma, o tempo psicológico, com toda sua imprecisão, é nossa aposta principal sobre a presença temporal na composição das toadas de Cururu, pois toda a referência religiosa/bíblica é feita a partir das lembranças do cururueiro, mesmo que isso não reflita exatamente o que consta no texto Sagrado.

Muito do que os cururueiros apresentam advém de uma transmissão de conhecimento por meio da oralidade, que transporta os princípios e valores de um para o outro, de geração a geração, mantendo-se a tradição aprendida com seus ascendentes.

Por tradição entendemos aquilo que persiste do passado no tempo atual, quando ela continua a agir e permanece sendo aceita por aqueles que a recebem e que, por conseguinte, continuarão a transmiti-la, passadas as gerações, em um certo grupo social de dada localização geográfica. Contudo, não é possível que se pense como imutável a transmissão desses hábitos, pois a cultura sofre influências históricas e sociais, sendo dificultosa sua reprodução idêntica ao que já foi um dia.

\section{CONSIDERAÇÕES FINAIS}

Compreendemos, pois, que a cultura é viva, mutável; também entendemos que o fato folclórico não é eterno e se vive, pode morrer. Já no final da década de 1970, quando a historiadora Eunice Rocha fez sua pesquisa, ela achou plausível mencionar sua preocupação com a média de idade dos cururueiros e o alheamento 
dos seus descendentes em aprender o Cururu e os valores relativos a essa manifestação cultural.

Passados mais de trinta anos, podemos afirmar que nada mudou [para melhor] no cenário sul-mato-grossense. Dos vários grupos que existiam praticando o Cururu, restam apenas uns poucos membros, que raramente se encontram para a brincadeira. O poder público procura realizar anualmente pelo menos um encontro com os poucos que restaram, mas o tempo vem consumindo essa manifestação cultural. Lembrando as palavras do "seu" Agripino que colocamos acima: "somos seis, sete, oito, nove, dez, doze cantadô de cururu", nada mais que isso. As preocupações de anos atrás são as mesmas, mas o que resta da prática folclórica não se compara ao que já foi um dia.

Consideramos, com tudo o que expusemos, que nossa pesquisa mostrou a pertinência de tratar tanto a narrativa do cururueiro, quanto da poética das toadas, sob a perspectiva dos conceitos propostos - tempo e resistência.

\section{REFERÊNCIAS BIBLIOGRÁFICAS}

BOSI, Alfredo. Narrativa e Resistência. In: Itinerários, Araraquara: 1996, p. 11-27. Disponível

$<$ http://piwik.seer.fclar.unesp.br/itinerarios/article/viewFile/2577/2207>. Acesso em: 11 nov. 2015, 22:45.

BOSI, Ecléa. Memória e Sociedade: lembranças dos velhos. 3. ed. São Paulo: Companhia das Letras, 1994.

CASCUDO, Luís da Câmara. Dicionário do Folclore Brasileiro. 3 ed. Rio de Janeiro: Ed. Ediouro, 1972.

DIÁRIO CORUMBAENSE. A História da Nossa Gente - Agripino Magalhães, cururueiro. Reportagem de Lívia Gaertner. Imagens de Ricardo Albertoni e Luiz Fernando. Edição de Lívia Gaertner e Ricardo Albertoni. Corumbá: Diarionline, 
2013. Disponível em: $<$ http://diarionline.com.br/index.php?s=noticia\&id=59242 $>$. Acesso em: 04 dez. 2015, 00:11:31.

IPHAN. Modo de Fazer Viola-de-Cocho. Brasília, IPHAN: 2009

NUNES, Benedito. O Tempo na Narrativa. 2. ed. São Paulo: Editora Ática, 1995.

ROCHA, Eunice Ajala. Uma expressão do folclore mato-grossense: cururu em Corumbá. Dissertação de Mestrado (PG em História da Cultura), PUC-RS. Porto Alegre, 1981.

SOUZA, João Carlos de. O caráter religioso e profano das festas populares: Corumbá, passagem do século XIX para o XX. Revista Brasileira de História, v. 24, $\mathrm{n}^{\mathrm{o}}$ 48, p. 332-351. São Paulo, 2004. Disponível em: $<$ http://www.scielo.br/scielo.php?script=sci arttext\&pid $=\mathrm{S} 0102-$

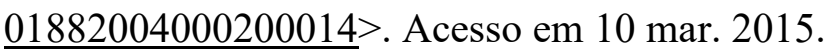

Recebido em 20/02/2017.

Aceito em20/03/2017. 